\title{
Desempenho animal e produtividade de pastagens tropicais no noroeste do Rio Grande do Sul
}

[Animal performance and productivity of tropical pasture in Northwest of Rio Grande do Sul]

\author{
A.R. Maixner ${ }^{1,4}$, F.L.F. Quadros ${ }^{1}$, D.P. Montardo ${ }^{2}$, G.V. Kozloski ${ }^{1}$, A. Noronha ${ }^{3}$, N.D. Aurélio ${ }^{1}$, G.E. \\ Rossi $^{1}$, E. Daniel ${ }^{1}$, M.S. Brum ${ }^{1}$, D.G. Bandinelli ${ }^{1}$ \\ ${ }^{1}$ Departamento de Zootecnia - UFSM \\ Avenida Roraima, 1000 \\ 97105-900 - Santa Maria, RS \\ ${ }^{2}$ Embrapa -Pecuária Sul - Bagé, RS \\ ${ }^{3}$ Fundação Estadual de Pesquisa Agropecuária - Ijuí, RS \\ ${ }^{4}$ Bolsista CNPq
}

\section{RESUMO}

Avaliou-se a produtividade do capim-elefante anão e do tifton 85 sob pastejo contínuo no noroeste do Rio Grande do Sul, utilizando-se 12 vacas da raça Holandesa, multíparas e com cerca de 100 dias de lactação. Foi aplicada a técnica dos animais reguladores para ajustes da carga animal de forma a manter a oferta de lâminas foliares de 4\%. No primeiro ano experimental, o capim-elefante anão e o tifton 85 apresentaram diferenças significativas quanto às taxas médias de acúmulo de lâminas foliares $(31,2 \mathrm{vs} 22,6 \mathrm{~kg} / \mathrm{ha} / \mathrm{dia}) \mathrm{e}$ produção animal (17,4 vs $20 \mathrm{~kg}$ de leite/vaca/dia). No segundo, o tifton 85 foi superior ao capim-elefante anão quanto à taxa de acúmulo de matéria seca de lâminas foliares $(38,8 \mathrm{vs} 21,9 \mathrm{~kg} / \mathrm{ha} / \mathrm{dia})$, capacidade de suporte (2157 vs $1084 \mathrm{~kg}$ de peso vivo/ha) e produções por área ( $70 \mathrm{vs} 41,3 \mathrm{~kg}$ de leite/ha/dia). No segundo ano, em relação ao primeiro, o tifton 85 manteve $88 \%$ da capacidade de suporte e $80 \%$ da produção por área, enquanto o capim-elefante anão apenas $46 \%$ e $56 \%$. A produção média de $17 \mathrm{~kg}$ de leite/vaca/dia indica um potencial pouco explorado das gramíneas tropicais em sistemas de produção de leite, especialmente na região Sul do Brasil.

Palavras-chave: Pennisetum purpureum, Cynodon dactylon, produção de leite, oferta de forragem

\begin{abstract}
Productivity of dwarf elephantgrass (Pennisetum purpureum Schum. cv. Mott) and tifton 85 (Cynodon dactylon $x$ Cynodon nlemfuensis) pastures was evaluated under continuous grazing, in the Northwest area of Rio Grande do Sul. Twelve multiparous Holstein cows, at 100 days of lactation were evaluated and the put-and-take technique was used to regulate the stocking rate to maintain $4 \%$ of leaf lamina on offer. In the first year, dwarf elephantgrass and tifton 85 were different in leaf accumulation rates (31.2 vs 22.6kg/ha/day) and animal production $(17.4 \mathrm{vs} 20 \mathrm{~kg}$ of milk/cow/day). In the second year, tifton 85 had higher leaf accumulation rates $(38.8 \mathrm{vs} 21.9 \mathrm{~kg} / \mathrm{ha} /$ day), stocking rate $(2,157 \mathrm{vs} 1,084 \mathrm{~kg}$ of live weight/ha), and production per area (70 vs $41.3 \mathrm{~kg}$ of milk/ha/day) than dwarf elephantgrass. Comparing the second to the first years, tifton 85 maintained $88 \%$ of stocking rate and $80 \%$ of production per area, while dwarf elephantgrass only $46 \%$ and $56 \%$, respectively. Average individual production of $17 \mathrm{~kg}$ of milk/cow/day indicates an unexplored potential of tropical grasses in dairy production systems, especially in the South of Brazil.
\end{abstract}

Keywords: Pennisetum purpureum, Cynodon dactylon, milk production, forage on offer

Recebido em 10 de dezembro de 2008

Aceito em 9 de julho de 2009

E-mail: armaixner@yahoo.com.br 


\section{INTRODUÇÃO}

No Rio Grande do Sul, predominam áreas com sistemas de produção de leite de pequena escala, com pouco capital disponível para investimentos e que utilizam mão de obra familiar como principal fonte de trabalho. São sistemas intensivos e mistos, com uso de animais de alto padrão genético e utilização de pastagens cultivadas, silagens e concentrados na alimentação do rebanho, integrando também lavouras de grãos e produção de leite como alternativas de diversificação das fontes de renda das propriedades e famílias rurais (Fernandes et al., 2004).

Dados do Censo Agropecuário do IBGE (Anuário..., 1996) mostram que cerca de $85 \%$ do leite produzido no RS é proveniente de propriedades de até 50 hectares. Isso caracteriza a produção de leite nesta região, econômica e socialmente, também como uma atividade essencial à manutenção das pequenas propriedades rurais, onde constitui fonte indispensável de renda. No entanto, nos últimos anos, parcela significativa dos produtores gaúchos tem abandonado a atividade leiteira (ou dela sendo excluídos), destacando-se como causa principal a baixa remuneração decorrente do baixo preço pago ao produtor e do alto custo de produção.

Estudos como os realizados por Hoffman et al. (1993), Vilela et al. (1996), White et al. (2002) e Fontaneli et al. (2005) têm demonstrado que sistemas de produção animal que utilizam pastagens como base alimentar podem ser mais viáveis e competitivos. Os fatores determinantes são o menor investimento em instalações e equipamentos e a menor despesa com mão de obra, insumos e alimentação, quando comparados ao sistema intensivo convencional (confinamento), embora este apresente índices produtivos mais elevados se comparado aos sistemas a pasto. São indispensáveis, portanto, práticas que pouco elevem os custos de produção e possibilitem o uso mais eficiente dos recursos disponíveis no sentido de otimizar a produção por animal e a produtividade por área.

Gramíneas tropicais perenes, como o capimelefante anão (Pennisetum purpureum Schum. cv. Mott) e o tifton 85 (Cynodon dactylon $\mathrm{x}$ Cynodon nlemfuensis), destacam-se em sistemas de produção de leite baseados em pastagens por produzirem alta quantidade de matéria seca (MS) digestível por área e por permitirem elevados níveis de produção animal (Martinez et al., 1980; Silva et al., 1994; Almeida et al., 2000b; Vilela et al., 2006). Entretanto, estudos avaliando o potencial dessas pastagens para produção de leite com animais em pastejo direto são menos comuns, particularmente na região Sul do Brasil.

A ampliação das áreas cultivadas com forrageiras perenes tropicais e o uso mais eficiente dessas pastagens podem contribuir para o aumento nas eficiências econômica e produtiva dos sistemas regionais de produção de leite durante o período estival. Além disso, a determinação do potencial produtivo das espécies em estudo pode constituir importante base de informação sobre sua utilização mais eficiente e o uso mais racional de alimentos concentrados e/ou conservados.

Este trabalho teve como objetivos avaliar a produtividade das pastagens de capim-elefante anão e tifton 85 e o desempenho de vacas em lactação sob pastejo contínuo.

\section{MATERIAL E MÉTODOS}

O experimento foi realizado no município de Palmeira das Missões, na região fisiográfica do Planalto Médio do Rio Grande do Sul, a 27 $53^{\circ}$ 'S, $53^{\circ} 26^{\prime} \mathrm{O}$ e altitude de $634 \mathrm{~m}$. O solo é classificado como latossolo vermelho distrófico típico (Unidade de Mapeamento Passo Fundo). Na classificação de Köppen, o clima da região é do tipo Cfa (subtropical úmido), com chuvas bem distribuídas durante o ano e temperatura média do mês mais quente acima de $22^{\circ} \mathrm{C}$.

O trabalho foi realizado nos anos agrícolas $2003 / 04$ e 2004/05. No primeiro ano agrícola foram avaliados três períodos -7 a 29 de novembro de 2003, 29 de novembro a 23 de dezembro de 2003 e 19 de janeiro a 17 de fevereiro de 2004 - e no segundo, dois períodos - 4 de dezembro de 2004 a 2 de janeiro de 2005 e 2 a 28 de janeiro de 2005 . As precipitações pluviométricas foram 23,9 e $53,9 \%$ abaixo dos índices normais climáticos da região, respectivamente para primeiro e segundo anos experimentais (Tab. 1). As temperaturas máximas médias foram 2,0 e 6,6\% acima dos dados normais climáticos regionais. 
Desempenho animal...

Tabela 1. Médias das temperaturas máxima (TMAX) e mínima (TMIN) e precipitação pluviométrica total mensal $(\mathrm{mm})$, observadas durante os períodos experimentais

\begin{tabular}{|c|c|c|c|c|c|c|c|c|c|c|c|c|}
\hline \multirow{3}{*}{ Meses } & \multicolumn{4}{|c|}{$\operatorname{TMAX}\left({ }^{\circ} \mathrm{C}\right)$} & \multicolumn{4}{|c|}{ TMIN $\left({ }^{\circ} \mathrm{C}\right)$} & \multicolumn{4}{|c|}{ Precipitação (mm) } \\
\hline & \multicolumn{4}{|c|}{ Ano } & \multicolumn{4}{|c|}{ Ano } & \multicolumn{4}{|c|}{ Ano } \\
\hline & 2003 & 2004 & 2005 & Normais & 2003 & 2004 & 2005 & Normais & 2003 & 2004 & 2005 & Normais \\
\hline Janeiro & - & 30 & 32,2 & 29,8 & - & 17,6 & 18,8 & 17,8 & - & 106 & 59,8 & 166 \\
\hline Fevereiro & - & 28,6 & - & 28 & - & 16,2 & - & 17,6 & - & 37,5 & - & 148 \\
\hline Novembro & 27 & - & - & 26,2 & 14,1 & - & - & 14,5 & 132,2 & - & - & 117 \\
\hline Dezembro & 29,8 & 30,7 & - & 29,2 & 16,3 & 17,5 & - & 16,1 & 148,5 & 81,6 & - & 145 \\
\hline
\end{tabular}

Fonte: Sistema Irriga ${ }^{\circledR}$

Os tratamentos experimentais foram constituídos de duas forrageiras tropicais: capim-elefante anão (Pennisetum purpureum Schum. cv. Mott) e tifton 85 (Cynodon dactylon $\mathrm{x}$ Cynodon nlemfuensis). A área experimental de 3,49 hectares (ha) foi dividida em quatro piquetes, de dimensões variando entre 0,78 e $1,05 \mathrm{ha}$, com duas repetições de área por tratamento, em delineamento experimental inteiramente ao acaso. Utilizaram-se 12 vacas da raça Holandesa, multíparas e com média de idades de 83 e 62 meses, pesos médios de 567 e $538 \mathrm{~kg}$, produções individuais médias de 18,8 e $17,8 \mathrm{~kg}$ de leite/vaca/dia e com 97 e 110 dias de lactação no início do primeiro e segundo anos de avaliações, respectivamente. As vacas foram selecionadas de modo a constituirem quatro grupos o mais homogêneos possível. Maixner et al. (2007) descrevem de forma mais detalhada as rotinas de manejo dos animais (ordenhas e acesso das vacas às pastagens, suplementação mineral e água), assim como a metodologia de implantação das pastagens e as práticas de adubação adotadas.

$\mathrm{Na}$ estação fria e até o início dos experimentos, o manejo alimentar dos animais foi constituído de pastejo direto em aveia preta (Avena strigosa Schreb) mais azevém (Lolium multiflorum Lam), suplementadas diariamente com cerca de $22 \mathrm{~kg}$ de silagem de milho (Zea mays L) e $12 \mathrm{~kg}$ de ração comercial por vaca. Reduziram-se gradualmente as quantidades de suplemento fornecido $(3 \mathrm{~kg}$ de silagem e $2 \mathrm{~kg}$ de ração/vaca/dia), de modo que os animais não recebessem suplementação a partir do início do período experimental. Para evitar efeitos residuais da suplementação, o desempenho animal foi registrado a partir da segunda semana do período experimental.

Foi adotado o sistema de pastejo contínuo com taxa de lotação variável, utilizando-se a técnica de animais reguladores (sistema put and take), em que cada tratamento recebeu de um a três animais-testes e um número variável de reguladores.

O peso das vacas foi estimado com o auxílio de fita métrica, relacionando a medida do perímetro torácico ao peso corporal. A carga animal foi ajustada sempre que necessário, mantendo as ofertas de lâminas foliares verdes em torno de $4 \%$ do peso vivo (PV).

A disponibilidade de massa de matéria seca total (MST) (kg/ha de MST) foi avaliada pelo método das estimativas visuais com dupla amostragem (Mannetje, 2000) a intervalos de 14 dias, aproximadamente. Foram realizadas 20 estimativas visuais, cinco delas coincidindo com coletas de forragem por meio de cortes. A forragem coletada foi separada nos componentes lâminas foliares; colmos e bainhas; e material morto e senescente, levada à estufa de ar forçado a aproximadamente $60^{\circ} \mathrm{C}$ e, após atingir peso constante, pesada para o cálculo da MST de cada corte. Com esses valores de MST, realizou-se análise de regressão para ajustar os cinco valores estimados em campo pelos avaliadores e os cinco valores registrados pelos cortes. Os 15 pontos restantes das estimativas visuais em campo foram incluídos nessas equações de regressão e, dessa forma, foi obtida a massa MST para cada piquete. A disponibilidade de massa de MS de lâminas foliares (MSLF) (kg/ha de MSLF) foi calculada pela participação percentual de MSLF na MST.

No tifton 85, as amostras foram coletadas utilizando-se um quadro metálico de $0,5 \times 0,5 \mathrm{~m}$ $\left(0,25 \mathrm{~m}^{2}\right)$, cortando-se as plantas ao nível do solo. No capim-elefante anão, foi utilizado um retângulo metálico de 1,0 x $1,2 \mathrm{~m} \quad\left(1,2 \mathrm{~m}^{2}\right)$, 
coletando-se a forragem a partir de $0,20 \mathrm{~m}$ do solo. Nesse tratamento, porém, para efeitos de cálculo, foi computada uma área útil amostrada de $1,68 \mathrm{~m}^{2}(1,4 \mathrm{x} 1,2 \mathrm{~m})$, com a adição de $0,4 \mathrm{~m}$ à largura de cada quadro, a fim de compensar a presença de falhas nas linhas de plantas.

As taxas de acúmulo de MS de lâminas foliares (TALF) e total (TAT) $(\mathrm{kg} / \mathrm{ha} /$ dia de MS) foram obtidas utilizando-se três gaiolas de exclusão de pastejo por piquete, conforme o método do triplo emparelhamento, com intervalos médios de 26 dias entre as avaliações.

Com os resultados de MSLF e TALF, MST e TAT e carga animal, foram calculadas, respectivamente, as reais ofertas diárias de MS de lâminas foliares (OLF) e total (OT), em kg de MS por $100 \mathrm{~kg}$ de PV por dia.

No modelo para a análise de variância dos dados, foram incluídos os efeitos dos animais-testes, das pastagens, dos períodos e suas interações. Usouse o teste Tukey ( $10 \%$ de probabilidade do erro Tipo I) para a comparação de médias. Os dados experimentais do primeiro ano sofreram transformação logarítmica decimal e todas as análises foram efetuadas utilizando-se o programa computacional SAS/1999.

\section{RESULTADOS E DISCUSSÃO}

A taxa de acúmulo de MS de lâminas foliares (MSLF) (kg/ha/dia) (TALF) foi, provavelmente, a variável influenciada de forma mais explícita pela peculiaridade das condições experimentais. No primeiro ano, a TALF média dos períodos no capim-elefante anão $(31,2 \mathrm{~kg} / \mathrm{ha} / \mathrm{dia})$ foi significativamente superior $(\mathrm{P} \leq 0,09)$ à média observada para o tifton $85(22,6 \mathrm{~kg} / \mathrm{ha} / \mathrm{dia})$ (Fig. 1A). No segundo ano, o tifton 85 apresentou valores médios de TALF $(38,8 \mathrm{~kg} / \mathrm{ha} / \mathrm{dia})$ superiores $(\mathrm{P} \leq 0,05)$ aos observados para $\mathrm{O}$ capim-elefante anão (21,9kg/ha/dia).

Além das condições climáticas atípicas que caracterizaram os anos agrícolas 2003/04 e 2004/05, a oferta de forragem permitida, em função do baixo acúmulo durante o primeiro ano de avaliações (cerca de 4\% de MS de lâminas foliares verdes), pode ter influenciado negativamente os resultados de produção de forragem no segundo ano e, consequentemente, os de capacidade de suporte e produção animal por área, nas pastagens de capim-elefante anão e tifton 85 .

Almeida et al. (2000a), ao avaliarem o capimelefante anão, encontraram taxa média de acúmulo de $59,0 \mathrm{~kg} / \mathrm{ha} / \mathrm{dia}$ de MSLF numa oferta de 3,8\% (kg MS de lâminas foliares por $100 \mathrm{~kg}$ PV por dia). Esses autores concluíram que essa oferta de forragem provocou alteração de características físicas do solo e redução do sistema radical das plantas, aumento pronunciado de espécies invasoras anuais e redução da TALF. Os resultados apontados por esses autores, aliados à deficiência hídrica no presente experimento, podem explicar os menores índices produtivos, especialmente do capim-elefante anão, no segundo ano em relação ao primeiro, e permitem sugerir que a oferta de lâminas foliares de cerca de 4\% levou à degradação do potencial produtivo desta forrageira. O comportamento do tifton 85 pode ser diverso ao capim-elefante anão neste nível de manejo, pois, embora existam poucos trabalhos científicos avaliando esse critério específico, este estudo indicou a capacidade de manutenção do potencial produtivo do tifton 85 à oferta de lâminas foliares de $4 \%$.

As taxas de acúmulo de MS total (MST) ( $\mathrm{kg} / \mathrm{ha} / \mathrm{dia})$ (TAT), em ambos os anos estudados, foram significativamente diferentes $(\mathrm{P} \leq 0,02)$, com valores médios finais de 40,2 e 77,7 para o capim-elefante anão e de 25,8 e $111,9 \mathrm{~kg} / \mathrm{ha} / \mathrm{dia}$ para o tifton 85 , respectivamente no primeiro e segundo anos de avaliação.

A influência das condições ambientais na redução do potencial forrageiro das pastagens também é percebida na observação dos resultados de disponibilidade de massa de forragem. No primeiro ano, foram registradas disponibilidades de massa de MSLF médias dos períodos de 1767 e $1665 \mathrm{~kg} / \mathrm{ha}$ para o capimelefante anão e o tifton 85 , respectivamente, não ocorrendo diferenças significativas $(\mathrm{P}=0,42)$ (Fig. 1B). No segundo ano, foram observadas diferenças significativas $(\mathrm{P}<0,01)$ nesta variável nas duas gramíneas, com valores médios de $587 \mathrm{~kg} / \mathrm{ha}$ para o capim-elefante anão e $1236 \mathrm{~kg} / \mathrm{ha}$ de MSLF para o tifton 85 . No capimelefante anão, além do estresse hídrico, a manutenção da oferta de $4 \%$ de lâminas foliares, no primeiro ano, pode ter potencialmente levado 
à perda de capacidade produtiva da pastagem. Cabe ressaltar que a menor disponibilidade de forragem no início das avaliações e a baixa acumulação de forragem, sobretudo no segundo ano, impediram a manutenção de níveis de massas de forragem mais adequados à conservação produtiva das pastagens de capimelefante anão. O tifton 85 apresentou relativa estabilidade das massas de forragem que garantiram sua maior persistência produtiva nos períodos avaliados. As disponibilidades de MST (kg/ha de MST) apresentaram diferenças significativas $(\mathrm{P}<0,01)$ entre os tratamentos nos dois anos, sendo registrados valores médios finais de 2400 e $801 \mathrm{~kg} /$ ha para o capim-elefante anão e de 6256 e $4274 \mathrm{~kg} /$ ha para o tifton 85 , respectivamente no primeiro e segundo anos.

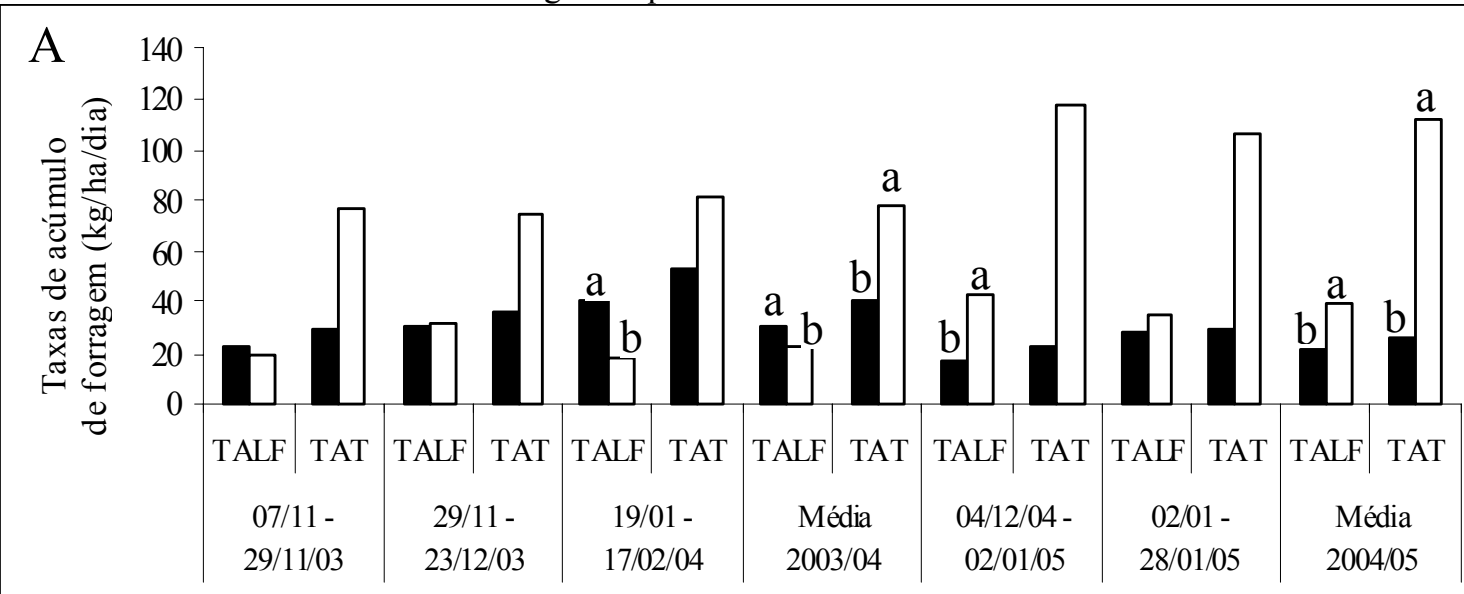

B

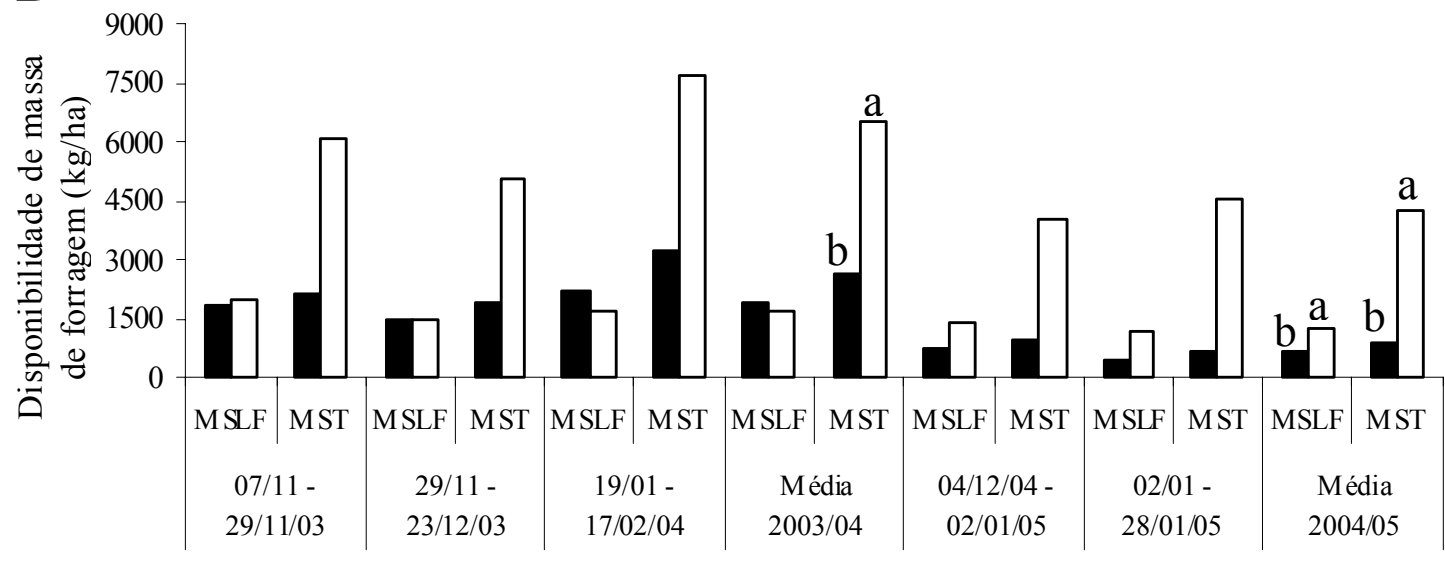

capim-elefante anão

$\square$ tifton 85

Letras minúsculas distintas indicam diferença significativa entre os tratamentos $(\mathrm{P} \leq 0,09)$.

Figura 1. A) Taxas de acúmulo de matéria seca de lâminas foliares (TALF) ( $\mathrm{kg} / \mathrm{ha} / \mathrm{dia})$ e de matéria seca total (TAT) (kg/ha/dia); B) disponibilidades de matéria seca de lâminas foliares (MSLF) (kg/ha) e de matéria seca total (MST) (kg/ha) nas pastagens de capim-elefante anão e tifton 85 .

Foram observados valores médios de ofertas reais de MS de lâminas foliares (kg de MSLF por $100 \mathrm{~kg}$ de PV por dia) (OLF) de 4,5 e 4,1\% para o capim-elefante anão e de $3,7 \%$ e $3,9 \%$ para o tifton 85 , respectivamente no primeiro e segundo anos (Fig. 2A). Não houve diferenças significativas $(P \geq 0,25)$ para esta variável, o que evidencia a eficiência e equidade do manejo proposto baseado na OLF. No primeiro ano, os reduzidos valores de OLF foram determinados pela falta de capacidade de suporte das pastagens de capim-elefante anão, condicionando os níveis 
observados aos maiores valores possíveis para manter o mínimo de três vacas testes por repetição. No segundo ano, a falta de capacidade de suporte foi agravada ainda mais pelas condições climáticas adversas (estiagem), optando-se, então, por aplicar oferta similar ao ano anterior a fim de manter a semelhança entre as condições experimentais nos dois anos de avaliação. As ofertas reais de MS total $(\mathrm{kg}$ de MST por $100 \mathrm{~kg}$ de PV por dia) (OT) apresentaram diferenças significativas $(\mathrm{P}<0,01)$ entre os tratamentos nos dois anos avaliados, sendo alcançados valores médios de 6,1 e $5,6 \%$ para o capim-elefante anão e de 13,9 e 13,1\% para o tifton 85 , respectivamente no primeiro e segundo anos.
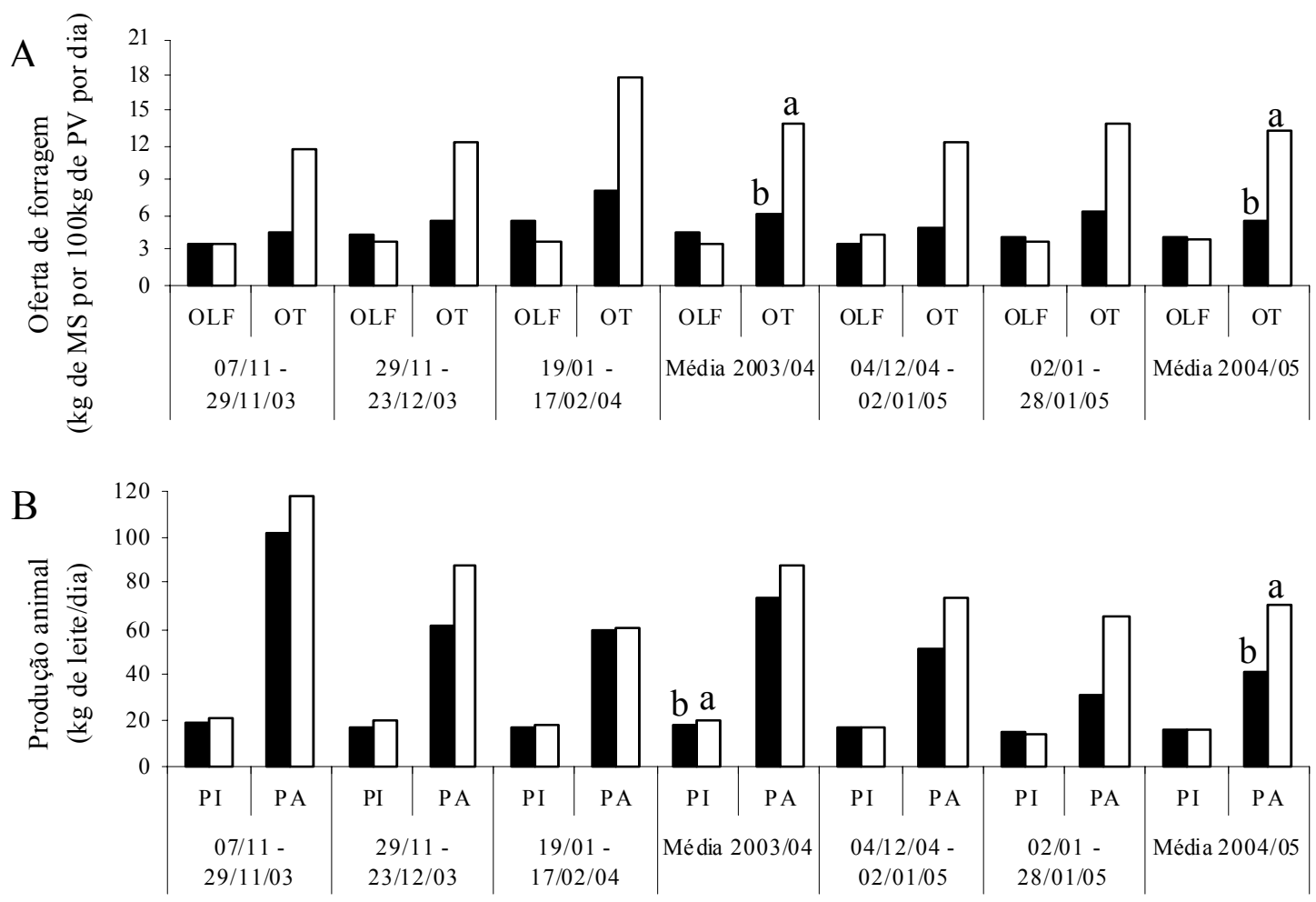

$\mathrm{C}$

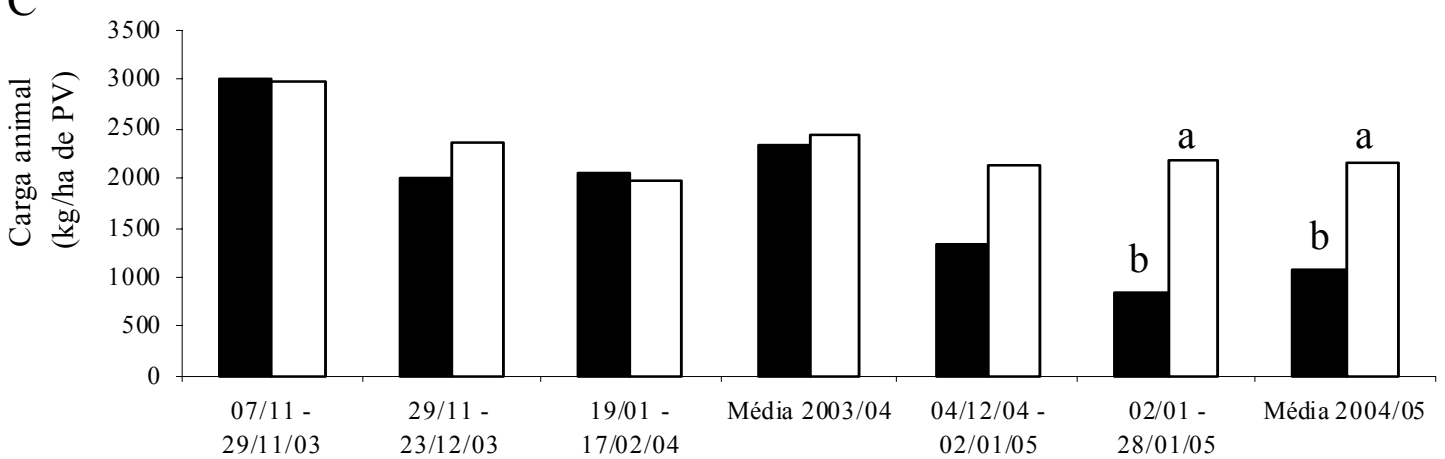

Capim Ele fante Anão

Tifton 85

Letras minúsculas distintas indicam diferença significativa entre os tratamentos $(\mathrm{P} \leq 0,06)$.

Figura 2. A) Oferta de matéria seca de lâminas foliares (OLF) (kg de matéria seca de lâminas foliares por $100 \mathrm{~kg}$ de peso vivo por dia) e oferta de matéria seca total (OT) ( $\mathrm{kg}$ de matéria seca total por $100 \mathrm{~kg}$ de peso vivo por dia); B) produção individual (PI) (kg de leite/vaca/dia) e produção por unidade de área (PA) (kg de leite/ha/dia); C) carga animal (kg/ha de PV) nas pastagens de capim-elefante anão e tifton 85. 
A produção de leite, no primeiro ano, apresentou diferença significativa $(\mathrm{P}=0,03)$ com valores médios de 17,4 e $20,0 \mathrm{~kg}$ de leite/vaca/dia para o capim-elefante anão e o tifton 85, respectivamente (Fig. 2B). No segundo ano, as produções de leite foram de 16,2 para o capimelefante anão e $15,6 \mathrm{~kg}$ de leite/vaca/dia para o tifton 85 , não ocorrendo diferenças significativas $(\mathrm{P}=0,51)$. Esses níveis de produtividade são mais elevados que os observados por Deresz (2001a,b) e Deresz et al. (2003), que verificaram produções médias de cerca de $12 \mathrm{~kg}$ de leite/vaca/dia, com animais de padrão genético Holandês x Zebu, em pastoreio rotativo com capim-elefante e sem suplementação concentrada, e equivalem aos de Fontaneli (2005), com produção média de 21,4kg de leite/vaca/dia, utilizando vacas da raça Holandesa, em pastoreio rotativo com capimelefante Napier e tifton 68 e suplementação de concentrado à base de milho. Os resultados do presente trabalho apontam para um potencial ainda inexplorado de produção de leite em gramíneas tropicais, acima de $12-14 \mathrm{~kg}$ de leite/vaca/dia (Deresz et al., 1994; Alvim et al., 1997; Deresz, 2001a,b; Deresz et al., 2003), que pode ser superior à média de $17 \mathrm{~kg}$ de leite/vaca/dia registrada nas duas estações de crescimento avaliadas. Dados referentes ao consumo de forragem e composição química das pastagens foram publicados por Maixner et al. (2007).

Almeida et al. (2000b) e Moraes (1991) ao avaliarem bovinos de corte em pastejo de capimelefante anão e pangola mais azevém mais trevo branco, respectivamente, apontaram para OLF da ordem de 11,3 e $12,4 \%$ como níveis apropriados ao máximo ganho médio diário (GMD). Estudando a resposta animal com distintas ofertas em duas variedades de capim-estrela e uma variedade de Cynodon nlemfuensis, Adjei et al. (1980) indicaram ofertas de forragem de 6 a $8 \%$ para o máximo GMD. É possível que o desempenho animal deste trabalho tenha sido limitado pela oferta de forragem utilizada e, assim, um novo patamar de produção leiteira pode ser potencialmente possível se a OLF de $3 \%$ empregada por Fontaneli (2005), ou a de 4\% aplicada neste trabalho forem aumentadas para 6 a $8 \%$.

Não houve diferença significativa $(\mathrm{P}=0,74)$, no primeiro ano, quanto à capacidade de suporte das pastagens, obtendo-se valores médios dos períodos de 2359 e $2445 \mathrm{~kg} / \mathrm{ha}$ de PV para o capim-elefante anão e o tifton 85 , respectivamente (Fig. 2C). No segundo ano, contudo, foram verificadas diferenças significativas $(\mathrm{P} \leq 0,06)$, com valores médios de $1084 \mathrm{~kg} /$ ha de PV para o capim-elefante anão e $2157 \mathrm{~kg} /$ ha de PV para o tifton 85 . Pode-se notar que o tifton 85 foi capaz de manter $88 \%$ da capacidade de suporte média no segundo ano em relação ao primeiro, enquanto no capim-elefante anão a carga média foi reduzida a menos da metade no segundo ano. Como consequência, a produção animal por unidade de área $(\mathrm{kg}$ de leite/ha/dia) foi afetada de forma análoga à capacidade de suporte das pastagens, visto que são variáveis intimamente relacionadas. Foram alcançados valores médios finais de 74,0 e $41,3 \mathrm{~kg}$ de leite $/$ ha/dia para o capim-elefante anão e de 88,2 e $70,0 \mathrm{~kg}$ de leite/ha/dia para o tifton 85 , respectivamente no primeiro e segundo anos avaliados, verificando-se diferença significativa $(\mathrm{P}=0,01)$ apenas no segundo ano (Fig. 2B). Os resultados obtidos no presente estudo são condizentes com os de Vilela et al. (2007) que, avaliando vacas da raça Holandesa manejadas em pastejo rotativo em coast-cross, encontraram produções por área de 77,8 e 94kg/ha com suplementação à base de milho de 3 e $6 \mathrm{~kg}$ de concentrado/vaca/dia, respectivamente. Nota-se que as produções por unidade de área obtidas no segundo ano são, respectivamente, 56 e $80 \%$ das produções obtidas no primeiro ano para capimelefante anão e tifton 85 , o que sugere o déficit hídrico acumulado como fator determinante também dos resultados obtidos nesta variável. É possível inferir que as espécies forrageiras avaliadas no presente estudo possuem características produtivas particulares que indicam a necessidade de maiores estudos sobre os critérios técnicos para o manejo adequado dessas pastagens.

\section{CONCLUSÕES}

A persistência produtiva das pastagens indica que o tifton 85 é menos sensível que o capimelefante anão à redução da produção forrageira e da capacidade de suporte sob condições adversas de clima e oferta de forragem média de $4 \%$ de lâminas foliares. A manutenção de oferta de lâminas foliares de $4 \%$ limita o desempenho das vacas, o que, quando aliada às condições climáticas adversas, prejudica a persistência produtiva das pastagens de capim-elefante anão e 
tifton 85 . A produção individual média de $17 \mathrm{~kg}$ de leite/vaca/dia indica um potencial pouco explorado das gramíneas tropicais em sistemas de produção de leite baseados em pastagem.

\section{AGRADECIMENTOS}

Ao Conselho Nacional de Desenvolvimento Tecnológico (CNPq) e à Fundação de Amparo à Pesquisa do Rio Grande do Sul (FAPERGS), pela concessão de bolsas de estudo e de iniciação científica. À Escola Estadual Técnica Celeste Gobbato, pela infra-estrutura e recursos humanos disponibilizados. À Fundação Estadual de Pesquisa Agropecuária (FEPAGRO - Noroeste e Missões), pela essencial contribuição de sua equipe técnica neste trabalho.

\section{REFERÊNCIAS BIBLIOGRÁFICAS}

ADJEI, M.B.; MISLEVY, P.; WARD, C.Y. Response of tropical grasses to stocking rate. Agron. J., v.72, p.863-868, 1980.

ALMEIDA, E.X.; MARASCHIN, G.E.; HARTHMANN, O.E.L. et al. Oferta de forragem de capim-elefante anão 'Mott' e a dinâmica da pastagem. Rev. Bras. Zootec., v.29, p.1281-1287, 2000a.

ALMEIDA, E.X.; MARASCHIN, G.E.; HARTHMANN, O.E.L. et al. Oferta de forragem de capim-elefante anão 'Mott' e o rendimento animal. Rev. Bras. Zootec., v.29, p.1288-1295, 2000b.

ALVIM, M.J.; VILELA, D.; LOPES, R.S. Efeitos de dois níveis de concentrado sobre a produção de leite de vacas da raça Holandesa em pastagem de coast-cross (Cynodon dactylon (L.) Pers). Rev. Bras. Zootec., v.26, p.967-975, 1997.

ANUÁRIO ESTATÍSTICO DO BRASIL. Rio de Janeiro: IBGE, 1996. v.56.

DERESZ, F. Influência do período de descanso da pastagem de Capim-elefante na produção de leite de vacas mestiças Holandês x Zebu. Rev. Bras. Zootec., v.30, p.461-469, $2001 \mathrm{a}$.

DERESZ, F. Produção de leite de vacas mestiças Holandês x Zebu em pastagem de capim-elefante, manejada em sistema rotativo com e sem suplementação durante a época das chuvas. Rev. Bras. Zootec., v.30, p.197-204, 2001 b.

DERESZ, F.; CÓSER, A.C.; MARTINS, C.E. et al. Utilização do capim-elefante (Pennisetum purpureum, Schum.) para a produção de leite. In: SIMPÓSIO BRASILEIRO DE FORRAGEIRAS E PASTAGENS, 4., 1994, Campinas. Anais... Campinas: CBNA, 1994. p.103199.

DERESZ, F.; MATOS, L.L.; MOZZER, O.L. et al. Produção de leite de vacas mestiças Holandês x Zebu em pastagem de capim-elefante, com e sem suplementação de concentrado durante a época das chuvas. Arq. Bras. Med. Vet. Zootec., v.55, p.334-340, 2003.
FERNANDES, E.N.; BRESSAN, M.; VERNEQUE, R.S. Zoneamento da pecuária leiteira da região sul do Brasil. Cienc. Rural, v.34, p.485-491, 2004.

FONTANELI, R.S. Produção de leite de vacas da raça Holandês em pastagens tropicais perenes no planalto médio do Rio Grande do Sul. 2005. 174f. Tese (Doutorado) Universidade Federal do Rio Grande do Sul, Porto Alegre.

FONTANELI, R.S.; SOLLENBERGER, L.E.; LITTELL, R.C. et al. Performance of lactating dairy cows managed on pasture-based or in freestall barn-feeding systems. J. Dairy Sci., v.88, p.1264-1276, 2005.

HOFFMAN, K.; MULLER, L.D.; FALES, S.L. et al. Quality evaluation and concentrate supplementation of rotational pasture grazed by lactating cows. J. Dairy Sci., v.76, p.26512663, 1993.

MAIXNER, A.R.; QUADROS, F.L.F.Q.; KOZLOSKI, G.V. et al. Consumo de forragem e desempenho de vacas Holandesas sob pastejo em gramíneas tropicais. Acta Scient., v.29, p.242-248, 2007.

MANNETJE, L'.t. Measuring biomass of grassland vegetation. In: MANNETJE, L'.t.; JONES, R.M. (Ed.). Field and laboratory methods for grassland and animal production research. Wallingford: CABI, 2000. p.151-177.

MARTINEZ, R.O.; RUIZ, R.; HERRERA, R. Milk production of cows grazing coastcross-1 bermudagrass (Cynodon dactylon). 1. Different concentrate supplementation levels. Cuban J. Agric. Sci., v.14, p.225232, 1980.

MORAES, A. Produtividade animal e dinâmica de uma pastagem de pangola (Digitaria decumbens Stent.), azevém (Lolium multiflorum Lam.) e trevo branco (Trifolium repens L.), submetida a diferentes pressões de pastejo. 1991. $200 \mathrm{f}$. Tese (Doutorado) - Universidade Federal do Rio Grande do Sul, Porto Alegre.

SILVA, D.S.; GOMIDE, J.A.; QUEIROZ, A.C. Pressão de pastejo em pastagem de capim-elefante anão (Pennisetum purpureum Schum. cv. Mott). 2. Efeito sobre o valor nutritivo, consumo de pasto e produção de leite. Rev. Soc. Bras. Zootec., v.23, p.453-464, 1994.

VILELA, D.; ALVIM, M.J.; CAMPOS, O.F. et al. Produção de leite de vacas holandesas em confinamento ou em pastagem de coastcross. Rev. Soc. Bras. Zootec., v.25, p.1228-1246, 1996.

VILELA, D.; FERREIRA, A.M.; RESENDE, J.C.; et al. Efeito do concentrado no desempenho produtivo, reprodutivo e econômico de vacas da raça Holandesa em pastagem de coast-cross. Arq. Bras. Med. Vet. Zootec., v.59, p.443-450, 2007.

VILELA, D.; LIMA, J.A.; RESENDE, J.C. et al. Desempenho de vacas da raça Holandesa em pastagem de coast-cross. Rev. Bras. Zootec., v.35, p.555-561, 2006.

WHITE, S.L.; BENSON, G.A.; WASHBURN, S.P. et al. Milk production and economics measures in confinement or pasture systems using seasonally calved Holstein and Jersey cows. J. Dairy Sci., v.85, p.95-104, 2002. 